\title{
Genetic Differentiation Within the Puccinia triticina Population in South America and Comparison with the North American Population Suggests Common Ancestry and Intercontinental Migration
}

\author{
M. E. Ordoñez, S. E. Germán, and J. A. Kolmer
}

First and third authors: United States Department of Agriculture-Agricultural Research Service Cereal Disease Laboratory, 1551 Lindig St., St. Paul MN, 55108; and second author: Instituto Nacional de Investigación Agropecuraria, La Estanzuela, CC 39173 Colonia, CP 70000 , Uruguay.

Accepted for publication 16 December 2009.

\begin{abstract}
Ordoñez, M. E., Germán, S. E., and Kolmer, J. A. 2010. Genetic differentiation within the Puccinia triticina population in South America and comparison with the North American population suggests common ancestry and intercontinental migration. Phytopathology 100:376-383.

Leaf rust, caused by Puccinia triticina, is the most prevalent and widespread disease of wheat in South America. The objective of this study was to determine whether genetically differentiated groups of $P$. triticina are currently present in South America and to compare the South American population with the previously characterized population in North America. In total, 130 isolates of $P$. triticina from the wheatgrowing regions of Argentina, Brazil, Chile, Peru, and Uruguay, mostly from the 1990s to 2008, were tested for virulence on 20 lines of wheat with single genes for leaf rust resistance and for molecular genotypes with 23 simple-sequence repeat (SSR) markers. After removal of isolates with identical virulence and SSR genotypes, 99 isolates were included for further analysis. Principal coordinate analysis plots indicated five

different groups of isolates based on SSR genotypes that also differed for virulence to leaf rust resistance genes. All pairs of groups, except for one pair, were significantly differentiated for SSR genotypes according to $R_{S T}$ statistics. All but two pairs of groups were significantly differentiated for virulence phenotype according to $\Phi_{P T}$ statistics. Isolates in all five groups had high values of fixation index for SSR alleles and linkage disequilibrium was high across all isolates that indicated the clonal reproduction of urediniospores. Only one of the five $P$. triticina groups from South America was differentiated for SSR genotypes from all of the six $P$. triticina groups from North America. The high degree of similarity for SSR genotype of isolates from both South America and North America suggested a common European origin of $P$. triticina that was introduced to both continents. The emergence of the same $P$. triticina virulence phenotypes with highly related SSR genotypes in the United States in 1996 and in Uruguay in 1999 indicated the likely intercontinental migration of these genotypes from Mexico to both South America and North America.
\end{abstract}

Leaf rust of wheat, caused by Puccinia triticina Erikss., is the most prevalent and widespread disease of wheat in South America (9). In Argentina, Brazil, Paraguay, and Uruguay, spring wheat cultivars are planted during the fall and winter months. Facultative wheat cultivars are also grown in higher latitudes in Argentina and Uruguay. In the Andean region of Chile, winter and facultative wheat cultivars are most commonly grown. Leaf rust is present throughout the year in Argentina and Uruguay, surviving on volunteer wheat during the summer. Because most of the cultivars are susceptible, yield losses can be $>50 \%$ if fungicides are not applied. The $P$. triticina population in Argentina, Brazil, and Uruguay is very dynamic because many different races are found every year (10) and newly released wheat cultivars often lose their effective resistance after a few years due to the increase of virulent races (9).

The first record of leaf rust on wheat in Uruguay is from 1907 (8), although it is likely the disease was present before then. Arthur (1) considered $P$. triticina to be native to southwest Asia; therefore, the fungus was likely introduced to South America with European settlement and the advent of wheat cultivation. The development of wheat cultivars with leaf rust resistance has a long

Corresponding author: J. A. Kolmer; E-mail address: jkolmer@umn.edu

doi:10.1094/PHYTO-100-4-0376

This article is in the public domain and not copyrightable. It may be freely reprinted with customary crediting of the source. The American Phytopathological Society, 2010 history in South America. In Uruguay (20), the Americano wheat cultivars that were derived from local landraces of European origin were selected in 1918. The Americano cultivars had good leaf rust resistance and yield characteristics and were used in crosses to develop subsequent cultivars in Argentina, Brazil, and Uruguay. Many of the catalogued leaf rust resistance genes (29) were derived from South American wheat cultivars.

Rajaram and Campos (35) indicated that the eastern Atlantic region of Argentina, Brazil, and Uruguay and the western Andean region of Chile and Peru were two separate epidemiological areas based on the differences in wheat stem rust and wheat stripe rust races and different infection levels on wheat lines with rust resistance genes grown in the different countries. However, some migration likely occurs because common rust races are found in both regions. Urediniospores of barley stripe rust race 24 were most likely transported over mountain passes between Argentina and Chile (36). The two regions also had common wheat stem rust races, wheat leaf rust races (41), and wheat stripe rust races (39) that also indicated movement of urediniospores between the two regions.

The development of simple-sequence repeat (SSR) DNA markers $(5,40)$ for $P$. triticina has greatly facilitated population biology studies of this widely dispersed and economically important rust fungus. $P$. triticina populations in Central Asia (21) and North America (32) had distinct groups of isolates that were strongly differentiated for SSR genotypes. In France (11), $P$. triticina isolates were differentiated for SSR genotype based on the host cultivar the isolates were collected from. 
The objective of this study was to determine whether distinct groups of $P$. triticina isolates based on SSR genotypes and virulence phenotypes were present in South America, which would indicate that different groups of the leaf rust fungus have been introduced over time, as was found in North America (32). A further objective was to determine whether there was any differentiation of $P$. triticina isolates from the eastern Atlantic region of Argentina, Brazil, and Uruguay compared with isolates from the western Andean region of Peru and Chile. The final objective was to compare the P. triticina population in South America with the population in North America (32) to determine whether the populations in the two continents were differentiated for SSR genotypes and virulence phenotypes, which would imply a lack of migration between the two continents.

\section{MATERIALS AND METHODS}

$\boldsymbol{P}$. triticina isolates. In total, $130 P$. triticina single uredinial isolates from South America were tested for SSR genotype and virulence phenotype. The collections included 11 isolates collected in Argentina from 2004 to 2006; 18 isolates from Brazil obtained in the mid-1990s; from Chile, 4 isolates collected in 1981-88 and 11 isolates in 2008; 10 isolates from Peru collected in 1981-95; and, from Uruguay, 2 isolates collected in 1985 and 1988,10 isolates collected in 1996, and 64 isolates collected from 2004 to 2006. Urediniospores of all isolates had been characterized previously for virulence and were kept afterward in either liquid nitrogen storage or in vacuum tubes at $4{ }^{\circ} \mathrm{C}$ prior to virulence testing and SSR genotyping.

Virulence phenotypes. Urediniospores of each isolate were used to inoculate 7-day-old seedlings of cv. Thatcher (CI 1003) as previously described (19) in order to increase urediniospores for virulence testing and DNA extraction. To determine the virulence phenotypes of the $P$. triticina isolates, five sets of four Thatcher near-isogenic lines of wheat, each carrying one leaf rust resistance gene, were used: set 1, Lrl (isogenic line RL6003), Lr2a (RL6000), Lr2c (RL6047), and Lr3 (RL6002); set 2, Lr9 (RL6010), Lr16 (RL6005), Lr24 (RL 6064), and Lr26 (6078); set 3, Lr3ka (RL6007), Lr11 (RL6053), Lrl7 (RL6008), Lr30 (RL6049); set 4, LrB (RL6047), Lr10 (RL6004), Lr14a (RL6013), and Lrl8 (RL6009); and set 5, Lr3bg (RL6042), Lr14b (RL6006), Lr20 (RL 6092), and Lr28 (RL6079). Thatcher was included as a susceptible control. Urediniospores of each isolate were spray inoculated to each set of 7- to 8-day-old differentials as previously described (19). Virulence phenotypes were determined 10 to 12 days after inoculation for each isolate on each Thatcher differential line using the scale described by Long and Kolmer (24). Infection types 0 to $2^{+}$(immune response to moderate uredinia with necrosis or chlorosis) were classified as avirulent and infection types 3 to 4 (moderate to large uredinia without chlorosis or necrosis) were classified as virulent. Each isolate was given a five-letter code based on virulence or avirulence to each of the five sets of four differentials as adapted from the nomenclature used by Long and Kolmer (24).

Molecular genotypes. DNA was extracted from 25 to $30 \mathrm{mg}$ of urediniospores of each isolate by first grinding the spores with $25 \mathrm{mg}$ of glass beads in a Savant FastPrep shaker (FP120; Holbrook, NY) for $20 \mathrm{~s}$, then using an OmniPrep extraction kit (GenoTech, St. Louis) according to instructions. Between 1 and $2 \mathrm{ng}$ of DNA was used for each polymerase chain reaction (PCR) amplification.

In all, 23 SSR microsatellite primer pairs developed from genomic libraries of $P$. triticina were used to characterize the collection: PtSSR 3, PtSSR 13, PtSSR 50, PtSSR 55, PtSSR 61, PtSSR 68-1, PtSSR 76, PtSSR 91, PtSSR 92, PtSSR 151A, PtSSR 152, PtSSR 154, PtSSR 158, PtSSR 161, PtSSR 164, PtSSR 173, PtSSR 184, PtSSR 186 (40), RB 1, RB 8, RB 11, RB 26, and RB 35 (5). Amplification and electrophoresis were carried out as previously described (32). Allele sizes in base pairs were scored visually for each primer pair by using a LI-COR (Lincoln, NE) 4200 or 4300 DNA sequencer that was calibrated with IRDye 700 molecular-weight size standards. DNA bands generated by each primer pair were compared with the allele sizes in the initial characterization of the SSR primers (40) and also with other $P$. triticina isolates previously characterized (31) using the same set of SSR primers. Separate DNA samples of isolates included in both previous studies and in the current study as controls had the same SSR genotypes.

Data analysis. The molecular weights for alleles at each of the 23 SSR loci for all isolates were recorded in the GenAlex 6 (33) format. Isolates from the same country that had identical virulence phenotypes and SSR genotypes were eliminated, which left 99 isolates for further analysis. A principal coordinate plot based on genetic distances (37) between all pairs of SSR genotypes using a geometric approach was generated in GenAlex 6 and was used to generate a two-dimensional principal coordinate analysis (PCA) plot. Grouping of the 99 isolates for further analysis was based on the grouping of SSR genotypes in the PCA plot. Neighbor-joining trees (1,001 total) of the SSR genotypes based on Euclidean distance were generated with Powermarker v3.25 (23), and the bootstrap values for support of individual isolates within each group were obtained with the CONSENSE program in Phylip 3.6 (7).

Averages of single-locus parameters for the isolates in the SSR groups-number of alleles, number of effective alleles, Shannon's information index $(I)$, observed heterozygosity $\left(H_{O}\right)$, expected heterozygosity $\left(H_{E}\right)$, and fixation index $\left(F_{I S}\right)$-were calculated with GenAlEx6. Genetic differentiation via the analysis of molecular variance (AMOVA) (6) with 999 permutations of the data set was calculated for the SSR genotypes with $R_{S T}$ that assumes a stepwise mutation model and by $F_{S T}$ that assumes the infinite alleles model. An analogous measure developed for binary data, $\Phi_{P T}$, was used to calculate differentiation of the virulence phenotypes in the SSR groups. Pairwise values of $R_{S T}, F_{S T}$, and $\Phi_{P T}$ were calculated via AMOVA among SSR groups.

A matrix of Jaccard coefficients derived from SSR allele differences of all pairs of isolates and a matrix of simple matching coefficients derived from virulence differences between isolates were generated in NTSys-pc 2.1 (Exeter Software, Setauket, NY). These matrices were compared with the Mantel (26) coefficient to determine the correlation between SSR genotype and virulence phenotype. The significance in differences of frequency (percent) of virulence to leaf rust resistance genes in different SSR groups of $P$. triticina isolates was determined with Fisher's exact test (38). Linkage disequilibrium across all SSR loci was calculated with the index of association $\left(I_{A}\right)$, and also with a measure corrected for the number of loci, $\bar{r}_{D}$, using MultiLocus v1.3 software (34). Tests of departure from random mating for both indices were done with 1,000 randomizations of the data set.

The SSR genotypes and virulence phenotypes of $127 P$. triticina isolates from the United States and Canada (32) that had been placed into six North American (NA) groups with the same set of SSR markers and host differentials were combined with the data of the 99 isolates from South America. Tests of genetic differentiation of isolate groups from both continents were done in GenAlex 6 via the AMOVA procedure, with 999 permutations of the combined dataset. $R_{S T}$ and $F_{S T}$ were used to determine differentiation of groups based on SSR genotypes and $\Phi_{P T}$ was used to determine differentiation based on virulence phenotypes. $R_{S T}$ pairwise values between SSR groups from both continents were also plotted as an unrooted tree with PHYLIP 3.6 (7) using the NEIGHBOR clustering option. Neighbor-joining trees of $R_{S T}$ (1,001 in total) were generated with Powermarker v3.25 and bootstrap values for branching of SSR groups was obtained with CONSENSE in Phylip 3.6. 


\section{RESULTS}

In total, $130 P$. triticina isolates from Argentina, Uruguay, Brazil, Chile, and Peru were tested for virulence phenotype and SSR genotype. Only one isolate of each virulence phenotypeSSR genotype from each country was retained, which left 99 isolates for the analyses (Table 1). The isolates were placed into South American (SA) groups using a PCA plot based on SSR genotypes (Fig. 1A) that resulted in five groups of isolates. SA-2 and SA-3 were the largest groups, with 49 and 32 isolates, respectively. SA-2 and SA-3 also had the largest number of virulence phenotypes, with 39 and 20, and SSR genotypes, with 25 and 14, respectively (Table 2). Groups SA-1, SA-4, and SA-5 were small with $<10$ isolates in each group. The isolates in SA-1, SA-2, SA-3, and SA-5 clustered into fairly discrete groups based on SSR genotypes (Fig. 1A), with bootstrap support values $>80 \%$ (Fig. 1B). The six isolates in SA-4 were more heterogeneous for SSR genotypes compared with the other groups, and had a bootstrap value $<80 \%$. The three isolates in SA-5 were all from Chile (Table 1). None of the isolates from Argentina were in SA-1 or SA-4. None of the isolates from Brazil were in SA-3 or SA-4. None of the isolates from Peru were in SA-3. In total, 74 virulence phenotypes and 55 SSR genotypes were characterized among the 99 isolates.

Among the five SA groups, the six isolates in SA-4 had the highest number of alleles per SSR locus, the highest number of effective alleles per locus, the highest Shannon gene diversity value, and the highest level of observed heterozygosity $\left(H_{o}\right)$ at each locus (Table 3). The nine isolates in SA-1 were the least diverse for these parameters. In the two largest groups, isolates in SA-2 had higher values for number of alleles per locus and for the Shannon information index $(I)$ compared with isolates in SA-3. Isolates in the two groups did not significantly differ for number of effective alleles, $H_{o}$, and expected heterozygosity $\left(H_{e}\right)$. Isolates in SA-3 had the highest value of $F_{I S}$, which indicated that the difference between $H_{o}$ and $H_{e}$ was the greatest in these isolates.

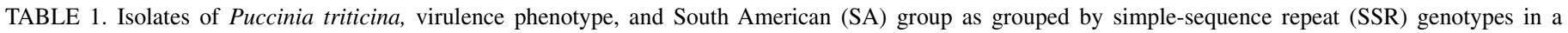
principal coordinate analysis plot

\begin{tabular}{|c|c|c|c|c|c|c|c|c|c|c|c|}
\hline $\begin{array}{l}\text { Isolate } \\
\text { no. }\end{array}$ & Country & Designation & $\begin{array}{c}\text { Year } \\
\text { collected }\end{array}$ & $\begin{array}{l}\text { Virulence } \\
\text { code }^{\mathrm{a}}\end{array}$ & $\begin{array}{l}\text { SA SSR } \\
\text { group }\end{array}$ & $\begin{array}{l}\text { Isolate } \\
\text { no. }\end{array}$ & Country & Designation & $\begin{array}{c}\text { Year } \\
\text { collected }\end{array}$ & $\begin{array}{l}\text { Virulence } \\
\text { code }^{\mathrm{a}}\end{array}$ & $\begin{array}{c}\text { SA SSR } \\
\text { group }\end{array}$ \\
\hline 1 & Brazil & 28.1 & 1996 & SDKSK & 1 & 50 & Uruguay & 28.1 & 2004 & MFPNQ & 2 \\
\hline 2 & Brazil & 29.1 & 1996 & TDTNM & 1 & 51 & Uruguay & 28.2 & 2004 & MFRJT & 2 \\
\hline 3 & Brazil & 33.1 & 1996 & TGDBM & 1 & 52 & Uruguay & 20.1 & 2004 & TDDST & 2 \\
\hline 4 & Chile & 84.1 & 1984 & SBJDH & 1 & 53 & Uruguay & 20.3 & 2004 & TFPSM & 2 \\
\hline 5 & Peru & 82.95 & 1982 & SBJGH & 1 & 54 & Uruguay & 997.1 & 2004 & CHTKT & 2 \\
\hline 6 & Peru & 82.94 & 1982 & SBJDH & 1 & 55 & Uruguay & 1116.1 & 2005 & TDGJK & 2 \\
\hline 7 & Uruguay & 16.3 & 2004 & SBDGK & 1 & 56 & Uruguay & 1147.1 & 2005 & MDRKT & 2 \\
\hline 8 & Uruguay & 6.2 & 2004 & SBDGK & 1 & 57 & Uruguay & 1274.1 & 2006 & MBRJT & 2 \\
\hline 9 & Uruguay & 87.21 & 1987 & SBJNH & 1 & 58 & Uruguay & 28.3 & 1996 & МCHJH & 2 \\
\hline 10 & Brazil & 27.1 & 1996 & LCGKH & 2 & 59 & Argentina & $415-1$ & 2004 & MDPSS & 3 \\
\hline 11 & Brazil & 37.1 & 1996 & SLGNH & 2 & 60 & Argentina & $474-1$ & 2006 & MFPNS & 3 \\
\hline 12 & Brazil & 25.2 & 1996 & LCGKH & 2 & 61 & Argentina & $502-1$ & 2006 & MCPSL & 3 \\
\hline 13 & Chile & 81.1 & 1981 & CBDSS & 2 & 62 & Argentina & $512-1$ & 2006 & MHTSQ & 3 \\
\hline 14 & Chile & 4044.4 & 1988 & LCGJH & 2 & 63 & Argentina & $480-1$ & 2006 & MCTSQ & 3 \\
\hline 15 & Peru & 82.1 & 1982 & SCDDK & 2 & 64 & Chile & $08-7.1$ & 2008 & MCFSP & 3 \\
\hline 16 & Peru & 81.1 & 1981 & SCDDK & 2 & 65 & Chile & $08-10.1$ & 2008 & MBDSS & 3 \\
\hline 17 & Peru & 4106.2 & 1987 & SCDDK & 2 & 66 & Chile & $08-11.2$ & 2008 & MCDSS & 3 \\
\hline 18 & Uruguay & 4.1 & 2004 & MDBJM & 2 & 67 & Uruguay & 25.1 & 2004 & MCPNL & 3 \\
\hline 19 & Uruguay & 4.2 & 2004 & MFGJM & 2 & 68 & Uruguay & 17.3 & 2004 & MCPSL & 3 \\
\hline 20 & Uruguay & 1369.1 & 2006 & SPGKH & 2 & 69 & Uruguay & 19.2 & 2004 & MFPNQ & 3 \\
\hline 21 & Uruguay & 5.2 .2 & 1996 & LCDKH & 2 & 70 & Uruguay & 36.1 & 2004 & MCDSS & 3 \\
\hline 22 & Uruguay & 7.2 .2 & 1996 & LCJKH & 2 & 71 & Uruguay & 1043.1 & 2005 & MHPSQ & 3 \\
\hline 23 & Uruguay & 11.3 & 1996 & TBDK & 2 & 72 & Uruguay & 1055.2 & 2005 & MCDSL & 3 \\
\hline 24 & Uruguay & 14.1 & 1996 & MBBJF & 2 & 73 & Uruguay & 1056.1 & 2005 & MFPSJ & 3 \\
\hline 25 & Uruguay & 29.2 & 1996 & LCGKH & 2 & 74 & Uruguay & 1293.1 & 2006 & MCPSL & 3 \\
\hline 26 & Uruguay & 85.1 & 1985 & LCGSH & 2 & 75 & Uruguay & 1400.1 & 2006 & MFPSS & 3 \\
\hline 27 & Argentina & 67.1 & 2006 & TDDKT & 2 & 76 & Uruguay & 1403.1 & 2006 & MMDSS & 3 \\
\hline 28 & Argentina & 509.1 & 2006 & TDDJT & 2 & 77 & Uruguay & 19.3 & 2004 & MFPNQ & 3 \\
\hline 29 & Argentina & 11.1 & 2006 & TPRFT & 2 & 78 & Uruguay & 29.2 & 2004 & MCPSQ & 3 \\
\hline 30 & Brazil & 41.2 & 1996 & MFRPR & 2 & 79 & Uruguay & 23.2 & 2004 & MCPSL & 3 \\
\hline 31 & Brazil & 19.3 & 1996 & MCRSH & 2 & 80 & Uruguay & 29.2 & 2004 & MCPSQ & 3 \\
\hline 32 & Brazil & 38.1 & 1996 & TDFTT & 2 & 81 & Uruguay & 6.1 & 2004 & MFDSS & 3 \\
\hline 33 & Brazil & 39.1 & 1996 & CBTNM & 2 & 82 & Uruguay & 25.2 & 2004 & MHPLL & 3 \\
\hline 34 & Brazil & 27.1 & 1996 & MBRJF & 2 & 83 & Uruguay & 23.1 & 2004 & MHPSQ & 3 \\
\hline 35 & Brazil & 26.1 & 1996 & MBRJT & 2 & 84 & Uruguay & 1295.1 & 2006 & MHPSQ & 3 \\
\hline 36 & Brazil & 27.2 & 1996 & MBRSF & 2 & 85 & Uruguay & 14.2 & 2004 & MCPSL & 3 \\
\hline 37 & Brazil & 31.1 & 1996 & CBTDR & 2 & 86 & Uruguay & 18.1 & 2004 & MBPSL & 3 \\
\hline 38 & Chile & $08-8.1$ & 2008 & TDBJK & 2 & 87 & Uruguay & 1010.1 & 2004 & MDPNS & 3 \\
\hline 39 & Peru & 4106.1 & 1987 & DBBST & 2 & 88 & Uruguay & 1072.1 & 2005 & MBPNS & 3 \\
\hline 40 & Uruguay & 3.3 & 2004 & TPRJK & 2 & 89 & Uruguay & 1222.1 & 2006 & MDPSS & 3 \\
\hline 41 & Uruguay & 1002.1 & 2004 & TDDJT & 2 & 90 & Uruguay & 1375.1 & 2006 & MDPNS & 3 \\
\hline 42 & Uruguay & 1021.1 & 2004 & MHRJQ & 2 & 91 & Chile & $08-3.3$ & 2008 & $\mathrm{CCDFF}$ & 4 \\
\hline 43 & Uruguay & 1132.1 & 2005 & TDDKT & 2 & 92 & Uruguay & 27.2 & 2004 & MCPSL & 4 \\
\hline 44 & Uruguay & 1283.1 & 2006 & MDRJT & 2 & 93 & Uruguay & 9.2 & 2004 & MHPSQ & 4 \\
\hline 45 & Uruguay & 1353.1 & 2006 & MFRKT & 2 & 94 & Uruguay & 33.1 & 1996 & NBQQK & 4 \\
\hline 46 & Uruguay & 1379.1 & 2006 & KDGJK & 2 & 95 & Peru & 4107.1 & 1987 & DBBJG & 4 \\
\hline 47 & Uruguay & 19.3 & 1996 & MCRSC & 2 & 96 & Peru & 4107.2 & 1987 & SCDDK & 4 \\
\hline 48 & Uruguay & 28.2 .1 & 1996 & CBTDR & 2 & 97 & Chile & 4042.1 & 1988 & DBBGJ & 5 \\
\hline \multirow[t]{2}{*}{49} & Uruguay & 41.2 & 1996 & MFDR & 2 & 98 & Chile & $08-4.3$ & 2008 & FCBQL & 5 \\
\hline & & & & & & 99 & Chile & $08-5.3$ & 2008 & FCBQB & 5 \\
\hline
\end{tabular}

a Five-letter code indicates virulence or avirulence to 20 Thatcher wheat isolines with different leaf rust resistance genes as adapted from Long and Kolmer (24). 
Linkage disequilibria between SSR loci across the 99 isolates was high, with an $I_{A}$ of 5.07 and $r_{D}$ of 0.247 .

The five SA groups were all significantly differentiated $(P<$ 0.05 ) for SSR genotypes with $F_{S T}$ statistics (not shown), with an overall $F_{S T}$ of 0.228 . Using $R_{S T}$ statistics, isolates in SA-3 and SA4 were not significantly differentiated whereas all other SA groups were differentiated $(P<0.05)$ (Table 4$)$, with an overall $R_{S T}$ of 0.754 . Based on virulence phenotypes, isolates in SA-2 and SA-4, and SA-4 and SA-5, were not significantly differentiated with $\Phi_{P T}$ statistics whereas all other SA groups were significantly differentiated $(P<0.05)$ for virulence phenotype (Table 4$)$, with an overall $\Phi_{P T}$ of 0.335 .

All isolates in SA-1 were virulent to leaf rust resistance genes $L r 1, L r 2 a, L r 2 c$, and $L r 17$ and were avirulent to $L r 26, L r 18$, and $L r 28$ (Table 5). Isolates in the two largest groups, SA-2 and SA-3, differed significantly for frequency of virulence to 12 of the 20 resistance genes that were tested. Nearly all isolates in SA-3 were avirulent to $\operatorname{Lr} 2 a, \operatorname{Lr} 2 c, \operatorname{Lr} 18$, and $\operatorname{Lr} 28$ and nearly all isolates were virulent to $L r B, L r 17$, and $L r 3 b g$. Isolates in SA-2 were more variable for virulence to the differentials compared with isolates in SA-3. Two isolates in SA-4 (94-NBQQK and 95-DBBJG) and the three isolates in SA-5 were unique compared with isolates in the other three groups because these were avirulent to $L r 2 a$ but virulent to $L r 2 c$. Isolates in SA-1, SA-2, and SA-3 all had the same high or low infection type to both $L r 2 a$ and $L r 2 c$. Three isolates in SA-4 (91-CCDFF, 92-MCPSL, and 93-MHPSQ) had virulence phenotypes characteristic of isolates in SA-3, and one isolate (96-SCDDK) had virulence characteristic of isolates in SA-1. For all 99 isolates, the Mantel correlation coefficient was $0.422(P=1.0)$ for comparison of the matrix of Jaccard similarity coefficients for SSR genotypes with the simple matching coefficients for virulence phenotypes with the complete set of 20 differentials.

The isolates were also grouped on the basis of country of origin and tested for differentiation of SSR genotypes with $R_{S T}$ and differentiation of virulence phenotypes with $\Phi_{P T}$ (Table 6). The isolates from Argentina were not significantly differentiated for SSR genotypes from isolates from Peru and Uruguay, and isolates from Peru were not significantly differentiated from isolates from Uruguay and Chile. Isolate 84.1 from Chile (4-SBJDH) (Table 1) and 87.21 from Uruguay (9-SBHNH) had identical SSR genotypes and were highly related for virulence phenotype. Isolates from the five countries were significantly differentiated $(P<0.05)$ for virulence phenotype, except for isolates from Uruguay and Argentina.

The SSR genotypes of the 99 isolates in the five SA groups from South America and 125 isolates from the six NA groups from North America (32) were analyzed jointly to determine the degree of genetic differentiation between SSR groups from the two continents. Based on $R_{S T}$ values, SA-1 was not significantly differentiated from NA-4, NA-5 and NA-1 were not significantly differentiated from SA-2, and SA-3 and SA-4 were not significantly differentiated from NA-3 (Fig. 2). NA-2 and SA-5 were significantly differentiated $(P<0.05)$ from all other NA and SA groups. The two isolates from durum wheat from Mexico in NA-6 were also significantly differentiated from all other groups. Several isolates from highly related NA and SA groups had identical SSR genotypes. Six isolates in SA-3 had the same SSR genotypes as six isolates in NA-3, and were highly related for virulence phenotype. One isolate in SA-2 had the same genotype as four isolates in NA-5 and one isolate in SA-1 had the same genotype as three isolates in NA-4. Isolate race 9 from Canada and isolate 6.2 from Uruguay were identical for virulence phenotype and SSR genotype. In all, 11 isolates in SA-2 differed at only one SSR locus with 25 isolates in NA-5. Based on $\Phi_{P T}$ values, all SA and NA groups were significantly differentiated $(P<0.05)$ for virulence phenotypes except for SA-4 and NA-1, SA-5 and NA-1, SA-1 and NA-4, and SA-4 and NA-4. The characteristic aviru- lence or virulence of the SA and NA SSR groups are listed in Table 7.

In the analysis of SSR variation for the combined datasets, $0 \%$ of the variation could be attributed to continental origin (Table 8). Variation among the NA and SA groups accounted for $55 \%$ of the total SSR variation, and the remaining $45 \%$ was found within individual isolates, reflecting the high values of $H_{o}$. Grouping of isolate SSR genotypes with PCA plots reduced variation among individual isolates within NA and SA groups to $0 \%$. Similarly, for virulence phenotypes associated with the NA and SA groups, 0\% of the variation could be attributed to continental origin. The majority of the virulence variation $(67 \%)$ was found among individual isolates within groups and the remainder (33\%) was found between the different groups.

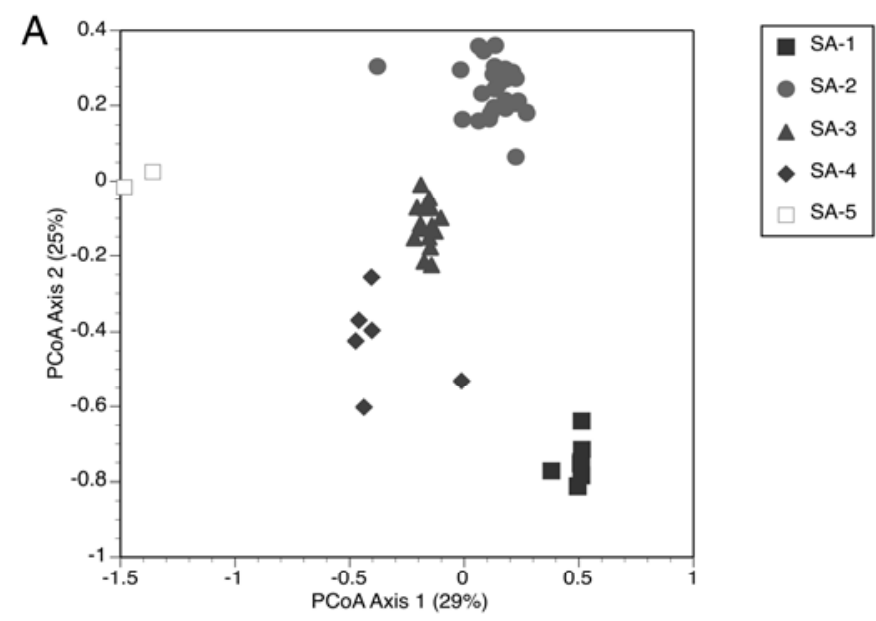

B

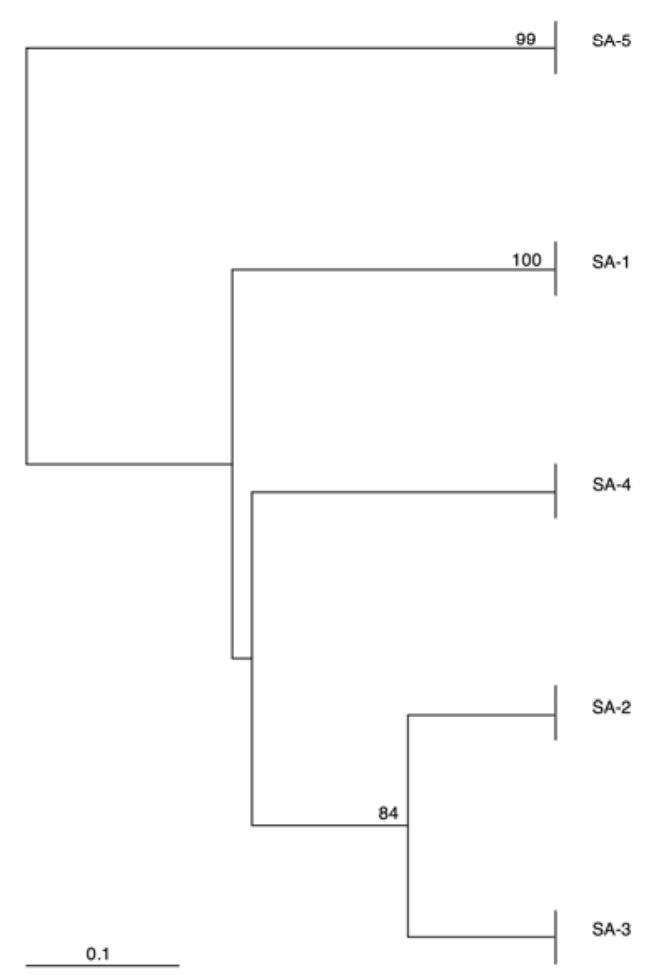

Fig. 1. A, Principal coordinate analysis plot of simple-sequence repeat (SSR) genotypes of 99 isolates of Puccinia triticina from South America based on genetic distance between genotypes. B, Neighbor-joining dendrogram of SSR genotypes in five South American (SA) groups based on average Euclidean distance between groups with bootstrap support values for individual isolates within each group. 


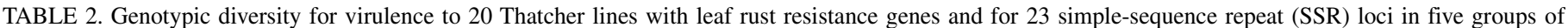
Puccinia triticina isolates from South America as grouped by SSR genotypes

\begin{tabular}{|c|c|c|c|c|c|c|}
\hline \multirow[b]{2}{*}{ Parameters } & \multicolumn{5}{|c|}{ South American (SA) SSR group } & \multirow[b]{2}{*}{ Total } \\
\hline & SA-1 & $\mathrm{SA}-2$ & $\mathrm{SA}-3$ & $\mathrm{SA}-4$ & $\mathrm{SA}-5$ & \\
\hline No. of isolates & 9 & 49 & 32 & 6 & 3 & 99 \\
\hline No. of virulence phenotypes & 6 & 39 & 20 & 6 & 3 & 74 \\
\hline No. of SSR genotypes & 6 & 25 & 14 & 6 & 2 & 55 \\
\hline
\end{tabular}

TABLE 3. Average of single-locus statistics of Puccinia triticina isolates from South America in groups of simple-sequence repeat (SSR) genotypes

\begin{tabular}{|c|c|c|c|c|c|c|}
\hline \multirow[b]{2}{*}{ Parameters $^{\mathrm{a}}$} & \multicolumn{5}{|c|}{ South American (SA) SSR group ${ }^{b}$} & \multirow[b]{2}{*}{ Total } \\
\hline & SA-1 & SA-2 & SA-3 & SA-4 & SA-5 & \\
\hline No. of alleles & $1.565(0.164)$ & $2.609(0.265)$ & $1.957(0.204)$ & $3.00(0.243)$ & $1.696(0.193)$ & $2.165(0.108)$ \\
\hline No. of effective alleles & $1.356(0.108)$ & $1.776(0.129)$ & $1.702(0.119)$ & $2.263(0.198)$ & $1.527(0.160)$ & $1.725(0.070)$ \\
\hline Shannon $I$ & $0.269(0.075)$ & $0.563(0.084)$ & $0.494(0.080)$ & $0.848(0.079)$ & $0.399(0.089)$ & $0.515(0.040)$ \\
\hline$H_{o}$ & $0.304(0.092)$ & $0.601(0.093)$ & $0.618(0.098)$ & $0.688(0.060)$ & $0.406(0.094)$ & $0.523(0.041)$ \\
\hline$H_{e}$ & $0.176(0.050)$ & $0.356(0.052)$ & $0.334(0.052)$ & $0.494(0.039)$ & $0.256(0.056)$ & $0.323(0.024)$ \\
\hline$F_{I S}$ & $-0.599(0.101)$ & $-0.516(0.088)$ & $-0.802(0.061)$ & $-0.380(0.050)$ & $-0.560(0.086)$ & $-0.553(0.036)$ \\
\hline
\end{tabular}

a $I=-\Sigma p_{i}\left(\ln p_{i}\right)$, where $p_{i}=$ frequency of $i$ th allele; $H_{o}=$ observed heterozygosity; $H_{e}=$ expected heterozygosity; and $F_{I S}=$ fixation index.

$\mathrm{b}$ Numbers in parentheses $=$ standard error.

TABLE 4. $R_{S T}$ values (top diagonal) and $\Phi_{P T}$ values (bottom diagonal) of genetic differentiation of simple-sequence repeat (SSR) genotypes and virulence phenotypes of Puccinia triticina isolates, respectively from South America in groups of SSR genotypes

\begin{tabular}{lccccc}
\hline & \multicolumn{5}{c}{ South American (SA) SSR group ${ }^{\mathrm{a}}$} \\
\cline { 2 - 6 } Group & SA-1 & SA-2 & SA-3 & SA-4 & SA-5 \\
\hline SA-1 & $\ldots$ & 0.240 & 0.378 & 0.559 & 0.972 \\
SA-2 & 0.226 & $\ldots$ & 0.581 & 0.771 & 0.981 \\
SA-3 & 0.636 & 0.338 & $\ldots$ & $0.017 *$ & 0.919 \\
SA-4 & 0.217 & $0.055^{*}$ & 0.288 & $\ldots$ & 0.902 \\
SA-5 & 0.537 & 0.343 & 0.615 & $0.113^{*}$ & $\ldots$
\end{tabular}

a All values significant at $P<0.05$, except those indicated with *, where $P>$ 0.05 .

\section{DISCUSSION}

In this study, distinct groups of $P$. triticina that differed for SSR genotype and for virulence phenotype were found in South America. These groups of isolates had very similar values for parameters related to allelic diversity and heterozygosity, as was found in groups of $P$. triticina SSR genotypes from North America (32), France (11), and Central Asia (21). All but one of the five SSR groups of $P$. triticina described in South America were closely related to equivalent groups in North America, which indicated that isolates in both continents may have originated from a common origin or that migration events have occurred between the two regions.

Seven of the nine isolates in SA-1 had S---- phenotypes that were virulent to $L r l, L r 2 a$, and $L r 2 c$ and also were virulent to Lr17. These isolates would have been classified as race 9 in the International Standard system for leaf rust races $(2,14,15)$ that was commonly used by many researchers in the 1920 s to 1960 s. Race 9 was the most common race in North America from 1930 to the mid-1940s $(14,15)$. Isolates in NA-4 were highly related to isolates in SA-1 for both SSR genotypes and virulence phenotypes, because four of the five isolates in NA-4 had race 9 virulence phenotypes. Isolates with a race 9 phenotype are currently rarely found in South America $(9,10)$ but were the most common isolates prior to 1954 in Argentina, Brazil, and Uruguay (41).

The two largest groups, SA-2 and SA-3, had isolates that were found throughout the wheat-growing regions in Argentina and Uruguay. The two groups differed for virulence to a number of $\mathrm{Lr}$ genes and also for SSR genotypes. Germán and Kolmer (10) characterized $P$. triticina isolates from Uruguay from 1989 to
TABLE 5. Frequencies of virulence (\%) to leaf rust resistance genes in isolates of Puccinia triticina from South America in groups of simplesequence repeat (SSR) genotypes ${ }^{\mathrm{a}}$

\begin{tabular}{|c|c|c|c|c|c|c|}
\hline \multirow[b]{2}{*}{ Gene } & \multicolumn{5}{|c|}{ South American (SA) SSR group } & \multirow[b]{2}{*}{ Difference $^{b}$} \\
\hline & SA-1 & SA-2 & SA-3 & SA-4 & SA-5 & \\
\hline Lrl & 100.0 & 87.8 & 100.0 & 66.7 & 0.0 & ns \\
\hline $\operatorname{Lr} 2 a$ & 100.0 & 38.8 & 0.0 & 16.7 & 0.0 & $*$ \\
\hline $\operatorname{Lr} 2 c$ & 100.0 & 38.8 & 0.0 & 50.0 & 100.0 & $*$ \\
\hline $\operatorname{Lr} 3$ & 22.2 & 75.5 & 100.0 & 50.0 & 66.7 & $*$ \\
\hline $\operatorname{Lr} 9$ & 0.0 & 8.2 & 3.1 & 0.0 & 0.0 & ns \\
\hline Lr16 & 11.1 & 4.1 & 15.6 & 16.7 & 0.0 & ns \\
\hline Lr24 & 22.2 & 44.9 & 31.3 & 0.0 & 0.0 & ns \\
\hline Lr26 & 0.0 & 51.0 & 78.1 & 66.7 & 66.7 & $*$ \\
\hline Lr3ka & 11.1 & 42.9 & 78.1 & 50.0 & 0.0 & $*$ \\
\hline Lrll & 66.7 & 65.3 & 6.3 & 16.7 & 0.0 & $*$ \\
\hline $\operatorname{Lr} 17$ & 100.0 & 38.8 & 100.0 & 66.7 & 0.0 & $*$ \\
\hline Lr30 & 11.1 & 46.9 & 81.3 & 33.3 & 0.0 & $*$ \\
\hline $\operatorname{Lr} B$ & 33.3 & 26.5 & 100.0 & 50.0 & 66.7 & $*$ \\
\hline Lrlo & 33.3 & 77.6 & 75.0 & 66.7 & 100.0 & $\mathrm{~ns}$ \\
\hline $\operatorname{Lr} 14 a$ & 66.7 & 100.0 & 96.6 & 83.3 & 0.0 & ns \\
\hline $\operatorname{Lr} 18$ & 0.0 & 30.6 & 0.0 & 16.7 & 0.0 & $*$ \\
\hline Lr3bg & 22.2 & 55.1 & 96.9 & 33.3 & 33.3 & $*$ \\
\hline $\mathrm{Lr} 14 b$ & 77.8 & 83.7 & 68.8 & 66.7 & 33.3 & ns \\
\hline Lr20 & 44.4 & 55.1 & 40.6 & 50.0 & 33.3 & ns \\
\hline $\operatorname{Lr} 28$ & 0.0 & 93.9 & 3.1 & 50.0 & 0.0 & $*$ \\
\hline
\end{tabular}

a Number of isolates in each group: SA-1 $=9$, SA-2 $=49$, SA-3 $=32$, SA-4 = 6 , and $\mathrm{SA}-5=3$.

b SA-2-SA-3 difference; ns = frequencies of SA-2 and SA-3 not significantly different, $P>0.05{ }^{*}=$ significantly different at $P<0.05$, from Fisher's exact test (38).

1993 that had virulence similar to the isolates in SA-1, SA-2, and SA-4 but did not find any isolates with virulence characteristic of isolates in SA-3. Isolates with virulence phenotypes found in SA3 with virulence to $\operatorname{Lrl7}$ were first detected in 1999 in Uruguay and Brazil (9). The distinct SSR genotypes and the number of virulence differences between isolates in SA-3 and the other SA groups suggest that the isolates in SA-3 were recently introduced to South America. The isolates in SA-2 were more variable for virulence to $L r$ genes and had higher average SSR diversity on a locus basis compared with isolates in SA-3, supporting the hypothesis that isolates in SA-3 are more recent. Isolates in SA-2 were closely related for SSR genotype to isolates in NA-1 and NA-5, and isolates in SA-3 were closely related to isolates in NA3 for SSR genotypes. Isolates with virulence phenotypes in NA-3 that were virulent to $\mathrm{Lrll}$ were first found in North America in 1996 (16,25). Based on amplified fragment length polymorphism 


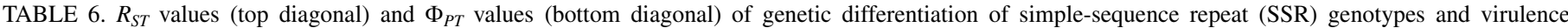
phenotypes of Puccinia triticina isolates, respectively, from South America

\begin{tabular}{|c|c|c|c|c|c|c|}
\hline \multirow[b]{2}{*}{ No. of isolates } & \multirow[b]{2}{*}{ Countries } & \multicolumn{5}{|c|}{ Countries } \\
\hline & & Argentina & Brazil & Chile & Peru & Uruguay \\
\hline 8 & Argentina & $\ldots$ & 0.344 & $0.110^{*}$ & $0.034 *$ & $0.000 *$ \\
\hline 14 & Brazil & 0.100 & $\ldots$ & 0.257 & 0.140 & 0.141 \\
\hline 11 & Chile & 0.173 & 0.138 & $\ldots$ & $0.128 *$ & 0.327 \\
\hline 8 & Peru & 0.415 & 0.262 & 0.225 & $\ldots$ & $0.000 *$ \\
\hline 58 & Uruguay & $0.000 *$ & 0.071 & 0.107 & 0.318 & $\ldots$ \\
\hline
\end{tabular}

a All values significant $P<0.05$, except those indicated with ${ }^{*}$, where $P>0.05$.

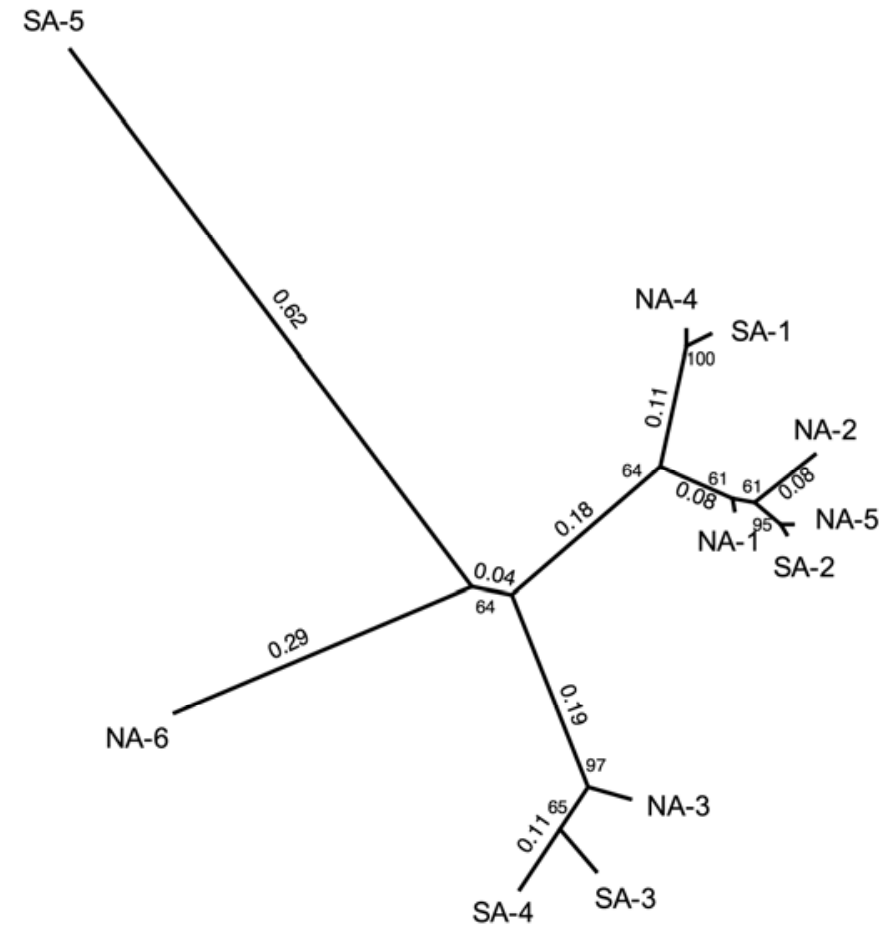

Fig. 2. Neighbor joining plot of values of $R_{S T}$ differentiation between South American (SA) and North American (NA) groups of Puccinia triticina simplesequence repeat genotypes. Values of $R_{S T}(<1.0)$ as indicated for major branches were derived with 999 permutations of the combined data set in GenAlex 6 (33). Bootstrap values $>60$ (1,001 trees total) for branch points are also indicated.

phenotypes (17) and SSR genotypes (32), it was hypothesized that these isolates with virulence to $L r 17$ were recently introduced to North America. Isolates in NA-3 and SA-3 may have originated from Mexico, because isolates with the same or similar virulence phenotypes were first found there in the mid-1990s (R. Singh, personal communication). Although isolates in SA-3 and NA-3, and SA-2 and NA-5, were not differentiated for SSR genotype, isolates in both pairs of groups were differentiated for a virulence phenotype that likely reflects the selective effect caused by the use of different $L r$ genes in wheat cultivars in the two continents. Isolates from durum wheat with identical or highly similar SSR genotypes to the two isolates in NA-6 from Mexico were previously found in Argentina and Chile (31).

The six isolates in SA-4 were more heterogeneous for virulence phenotype and SSR genotype compared with the other SA groups and did not cluster with isolates in the other groups for SSR genotypes in the PCA ordination. Isolates in SA-4 had virulence phenotypes similar to isolates in SA-3, SA-1, and SA-5. Isolates in SA-4 may be a composite of variant isolates that have their origins in other SA groups.

The three isolates in SA-5 were unique in that these had very different SSR genotypes compared with all other SA and NA groups. These isolates were collected in Chile in 1988 and 2008
TABLE 7. Groups of Puccinia triticina isolates from North America (NA) and South America (SA) based on simple-sequence repeat (SSR) genotypes and their characteristic avirulence or virulence to Thatcher wheat lines isogenic for leaf-rust-resistance genes and the equivalent International Standard race designations $\mathrm{s}^{\mathrm{a}}$

\begin{tabular}{|c|c|c|}
\hline SSR group & Characteristic avirulence/virulence & $\begin{array}{l}\text { International standard } \\
\text { race equivalents }\end{array}$ \\
\hline NA-1 & $1,2 \mathrm{a}, 2 \mathrm{c}, 3,28 / 14 \mathrm{a}$ & 1 \\
\hline \multirow[t]{4}{*}{ NA-2 } & $1,2 \mathrm{a}, 3 / 2 \mathrm{c}, 28$ & \\
\hline & $1,2 \mathrm{a} / 2 \mathrm{c}, 3,28$ & \\
\hline & $2 \mathrm{a} / 1,2 \mathrm{c}, 3,28$ & \\
\hline & $1,2 \mathrm{a}, 3 / 2 \mathrm{c}, 28$ & $6,11,12,37$ \\
\hline \multirow[t]{3}{*}{ NA-3 } & $1,2 \mathrm{a}, 2 \mathrm{c}, 28 / 3,3 \mathrm{bg}, 17, \mathrm{~B}$ & \\
\hline & $2 \mathrm{a}, 2 \mathrm{c}, 28 / 1,3,3 \mathrm{bg}, 17, \mathrm{~B}$ & \\
\hline & $28 / 1,2 \mathrm{a}, 2 \mathrm{c}, 3,3 \mathrm{bg}, 17, \mathrm{~B}$ & $2,5,21$ \\
\hline \multirow[t]{2}{*}{ NA-4 } & $3 / 1,2 \mathrm{a}, 2 \mathrm{c}, 17,28$ & \\
\hline & $---/ 1,2 \mathrm{a}, 2 \mathrm{c}, 3,3 \mathrm{ka}, 11,17,30$ & 9,21 \\
\hline \multirow[t]{2}{*}{ NA-5 } & $2 \mathrm{a}, 2 \mathrm{c}, 3 \mathrm{bg}, 17, \mathrm{~B} / 28$ & \\
\hline & $3 \mathrm{bg}, 17, \mathrm{~B} / 1,2 \mathrm{a}, 2 \mathrm{c}, 3,28$ & 5,13 \\
\hline NA-6 & $1,2 \mathrm{a}, 2 \mathrm{c}, 3,14 \mathrm{a}, 28 / 10,14 \mathrm{~b}$ & 1 \\
\hline \multirow[t]{2}{*}{ SA-1 } & $3 / 1,2 \mathrm{a}, 2 \mathrm{c}, 17,28$ & \\
\hline & $---/ 1,2 a, 2 c, 3,17,28$ & 9,21 \\
\hline \multirow[t]{5}{*}{ SA-2 } & $---/ 1,2 a, 2 c, 3,28$ & \\
\hline & $2 \mathrm{a}, 2 \mathrm{c} / 1,3,28$ & \\
\hline & $2 \mathrm{a}, 2 \mathrm{c}, 3 / 1,28$ & \\
\hline & $3 / 1,2 \mathrm{a}, 2 \mathrm{c}, 17,28$ & \\
\hline & $1,2 \mathrm{a}, 2 \mathrm{c} / 3,28$ & $2,5,9,17,21$ \\
\hline SA-3 & $28 / 1,3,3$ bg, $17, \mathrm{~B}$ & 5 \\
\hline \multirow[t]{5}{*}{ SA-4 } & $1,2 \mathrm{a}, 2 \mathrm{c}, 28 / 3,17,3 \mathrm{bg}, \mathrm{B}$ & \\
\hline & $2 \mathrm{a}, 2 \mathrm{c}, 28 / 1,3,17,3 \mathrm{bg}, \mathrm{B}$ & \\
\hline & $1,2 \mathrm{a}, 3,28 / 2 \mathrm{c}$ & \\
\hline & $3 / 1,2 \mathrm{a}, 2 \mathrm{c}, 17,28$ & \\
\hline & $2 \mathrm{a}, 3 / 2 \mathrm{c}, 28$ & $2,5,11,9,37$ \\
\hline \multirow[t]{2}{*}{ SA-5 } & $1,2 \mathrm{a}, 3,28 / 2 \mathrm{c}$ & \\
\hline & $1,2 \mathrm{a}, 28 / 2 \mathrm{c}, 3$ & 11,12 \\
\hline
\end{tabular}

${ }^{a}$ NA groups given by Ordoñez and Kolmer (32). International Standard race designations given by Chester (2), Johnson (14), and Johnston et al. (15).

from winter wheat plots and may represent an isolated group of $P$. triticina that is found in the intermountain valleys of the Andes that are not currently found in the major wheat-producing areas in Argentina and Uruguay.

As expected based on geographical proximity, there was no significant differentiation of SSR genotypes based on $R_{S T}$ or virulence phenotypes based on $\Phi_{P T}$ between isolates from Uruguay and Argentina. The lack of geographic barriers and the exchange of wheat germplasm (9) accounts for the similar $P$. triticina population between the two countries. In this study, all of the isolates from Brazil were collected previous to 1996; thus, none of the isolates in SA-3, which were collected after 2004, were included. The differentiation of the isolates from Brazil for SSR genotype compared with all other countries was due to the lack of more recent collections from Brazil. In recent years, the most common virulence phenotypes found in Brazil were also commonly found in Argentina and Uruguay (9), confirming that the eastern Atlantic region is a single epidemiological zone for wheat leaf rust (36). The isolates from Chile and Argentina, Peru and Argentina, and Uruguay and Peru were not differentiated for SSR genotypes, which indicated that some movement of uredinio- 
spores occurs between the western Andean region and the eastern Atlantic region, as indicated by Saari and Prescott (36). All pairs of countries except for Argentina-Uruguay were differentiated for virulence phenotype. This is likely due to differences in $\mathrm{Lr}$ genes in the wheat cultivars the collections were sampled from. The high level of linkage disequilibria for SSR loci across all isolates from South America and the high levels of observed heterozygosity in all SA groups provided strong evidence for clonal reproduction $(3,12)$ of urediniospores throughout this region. The primary alternate host for $P$. triticina, Thalictrum speciosissimum, is not present in South America (4).

The high degree of similarity in SSR genotypes between $P$. triticina populations in North America and South America likely resulted from common origins of the founding introductions to both continents, followed by intercontinental migration. The center of origin for $P$. triticina is likely the western Asia region bounded by the Mediterranean Sea, the Caspian Sea, and the Caucasus (4). Leaf rust on cultivated emmer wheat and common wheat would have spread to Europe from western Asia. Colonists from Europe likely carried the initial introductions of $P$. triticina to the New World as agricultural settlements were established in the 15th and 16th centuries. Urediniospores of $P$. triticina can retain viability in dried leaf tissue for a period of up to 6 months if kept at cool temperatures above freezing (J. A. Kolmer, unpublished data). The straw bedding used for settler's livestock would likely have included dried leaves with uredinial infections. An alternative explanation is that urediniospores of $P$. triticina were wind transported from Europe after the establishment of wheat cultivation in the New World. If this occurred, it was likely a rare event because the current virulence phenotypes in Western Europe and North America are highly distinct $(11,16)$.

In early surveys of $P$. triticina, International Standard race 9 (S--phenotypes) was by far the most common race in Europe, North America, and South America before 1940 (4). At this time, leafrust-susceptible wheat cultivars were still grown in North America and Europe; thus, selective effects due to resistance genes would be negligible, although resistant cultivars had been grown in South America since at least 1918 (20). The preponderance of race 9 on all three continents likely reflects the introduction of this race to the Americas directly from Europe. The most common races in North America (race 9, race 12, and race 21) (Table 7) and South America (race 9, race 37, and race 2) previous to 1940 were all found in Europe during the same time (4).

Isolates with virulence phenotypes characteristic of isolates in SA-3 and NA-3 were found in Mexico prior to their occurrence in North America and South America; therefore, the most probable scenario is that Mexico was the common origin of these introductions. However, it is difficult to envision urediniospores being wind carried from Mexico to the Southern Cone region of South America because the equatorial intertropical convergence zone (13) would likely operate as a barrier for spore movement directly between North America and Mexico with South America. It is more likely that isolates in SA-3 were introduced to South
America from either Mexico or North America by human activities. It has been speculated that soybean rust (13) was carried from the Caribbean region of South America north of the equator to the southern United States by hurricane Ivan. However, there is no evidence of spores being carried by winds from north to south. Other fungal pathogens of cereals have recently been introduced to new continents by human activities. Barley stripe rust was introduced from Europe to South America in 1975 and then to Mexico in 1990 and the United States in 1991 by human activities (27). Stripe rust of wheat was carried to Australia from Europe by a single human-assisted introduction in 1979 (42). Stem rust of wheat, caused by P. graminis f. sp. tritici, also originated in southwestern Asia and migrated to the Americas from Europe (1). McCallum et al. (28) determined that 20 isolates of $P$. graminis from South America were similar enough for virulence, random amplified polymorphic DNA, and isozyme markers with isolates from Europe and North America to support the hypothesis that the isolates were all derived from a common origin. Munkacsi et. al. (30) examined populations of Ustilago maydis, causal organism of maize smut, in South America, North America, and Mexico, which is the center of origin for both maize and $U$. maydis. Five distinct populations (two in Mexico, two in South America, and one in North America) were described, with little migration between the populations. In this case, differentiation of the pathogen populations due to host selection occurred after migration from the center of origin.

The $P$. triticina population in South America is characterized by a large number of virulence phenotypes that can be placed into different groups based on SSR genotypes with some degree of correlation between the two types of markers. The $P$. triticina populations in France (11), North America (32), and Central Asia (21) also showed a similar relationship between virulence phenotypes and grouping of isolates based on SSR genotypes, which would be expected because all of these populations reproduce by the clonal production of urediniospores. In NA-3 and SA-3, nearly all isolates were virulent to $\operatorname{Lr} 3 b g, \operatorname{Lr} 17$, and $\operatorname{LrB}$, and avirulent to $L r 28$. Similarly, in NA-2 and SA-5, nearly all isolates were avirulent to $L r 2 a$ and virulent to $L r 2 c$. Yet virulence to other genes such as Lr24 and Lr26 occurs at random and is not associated with any particular SSR group.

Because many wheat cultivars in South America are susceptible to leaf rust, there is a large population of $P$. triticina that can oversummer on volunteer wheat and is present year round (9). In such a large population, bottlenecks due to seasonal extinction would be rare, and random mutations to increased virulence among isolates within the SSR groups would be a regular event. Ordoñez and Kolmer (32) showed that phenotypes within the NA3 and NA-5 SSR groups in North America almost always differed by a single virulence to the next closest phenotype, indicating the likelihood of single-step mutations. The long use of wheat cultivars in South America with effective $L r$ genes (9) has resulted in a dynamic $P$. triticina population in which virulent phenotypes quickly increase in response to host resistance genes.

TABLE 8. Analysis of variance for simple-sequence repeat (SSR) allele variation and virulence variation in isolates of Puccinia triticina from South America and North America

\begin{tabular}{|c|c|c|c|c|c|}
\hline Source of variance & Variance & Total variance $(\%)$ & $R$ statistic & $\Phi$ statistic & Probability \\
\hline \multicolumn{6}{|l|}{ SSR allele variation } \\
\hline Among continents & 0.00 & 0.00 & $R_{R T} 0.000$ & $\ldots$ & 1.000 \\
\hline Among groups within continents & $5,448.00$ & 55.00 & $R_{S T} 0.609$ & $\ldots$ & 0.001 \\
\hline Within individual isolates & $4,511.00$ & 45.00 & $R_{I T} 0.317$ & $\ldots$ & 0.001 \\
\hline Total variation & $9,960 \mathrm{v}$ & 100.00 & $\ldots$ & $\ldots$ & $\ldots$ \\
\hline \multicolumn{6}{|l|}{ Virulence variation } \\
\hline Among continents & 0.00 & 0.00 & $\ldots$ & $\Phi_{R T} 0.000$ & 0.990 \\
\hline Total & 4.06 & 100.00 & $\ldots$ & $\ldots$ & $\ldots$ \\
\hline
\end{tabular}


The possibility of migration of $P$. triticina between North America and South America has implications for use of leaf-rustresistance genes in both continents. Genes $\operatorname{Lrl3}, \operatorname{Lrl7}, \operatorname{Lrl6}$, Lr24, Lr26, and Lr34 are present in wheat cultivars in both continents. The migration of $P$. triticina either through Mexico or directly between continents could introduce isolates from new groups of SSR genotypes that have virulence to effective resistance genes in wheat cultivars. The arrival of MCDSS and other similar phenotypes in 1999 in South America caused widespread leaf rust epidemics in Uruguay on cvs. Estanzuela Pelon 90 and INIA Mirlo, which both have Lr17. Other phenotypes in SA-3 with virulence to Lrl6 (9) have caused losses in Uruguay and Argentina. Phenotypes in NA-3 that are derived from MCDSS with virulence to $L r 24$ and $L r 41$ (19) have continued to cause yield losses on wheat cultivars with these genes in the United States. Strategic use of different $L r$ genes in the two continents is not practical; therefore, greater emphasis will ultimately need to be placed on selection of wheat cultivars with combinations of resistance genes that have proven to be durable over time (18) or combinations of non-race-specific resistance genes (22) that do not have strong selective effects on $P$. triticina populations.

\section{ACKNOWLEDGMENTS}

We thank R. Madariaga and A. Barcellos for collections of P. triticina and $\mathrm{M}$. Hughes and $\mathrm{K}$. Xiao for assistance with the figures.

\section{LITERATURE CITED}

1. Arthur, J. C. 1929. The Plant Rusts (Urediniales). John Wiley \& Sons, New York.

2. Basile, R. 1957. A diagnostic key for the identification of physiologic races of Puccinia rubigo-vera grouped according to a unified numeration scheme. Plant Dis.Rep. 41:508-511.

3. Birky, C. W. 1996. Heterozygosity, heteromorphy, and phylogenetic trees in asexual eukaryotes. Genetics 144:427-437.

4. Chester, K. S. 1946. The Nature and Prevention of the Cereal Rusts as Exemplified in the Leaf Rust of Wheat. Chronica Botanica, Waltham, MA.

5. Duan, X., Enjalbert, J., Vautrin, D., Solignac, C., and Giraud, T. 2003. Isolation of 12 microsatellite loci, using an enrichment protocol, in the phytopathogenic fungus Puccinia triticina. Mol. Ecol. Notes 3:65-67.

6. Excoffier, L., Smouse, P. E., and Quattro, J. M. 1992. Analysis of molecular variance inferred from metric distances among DNA haplotypes: Application to human mitochondrial DNA restriction data. Genetics 131:479-491.

7. Felsenstein, J. 1989. PHYLIP Phylogeny inference package (version 3.2). Cladistics 5:164-166.

8. Gassner, G. 1907. Estudio de los hongos de al Republica Oriental del Uruguay: Puccinia triticina Erikss. Rev. Secc. Agron. Univ. Montevideo 2:115-118.

9. Germán, S. E., Barcellos, A., Chaves, M., Kohli, M., Campos, P., and de Viedma, L. 2007. The situation of common wheat rusts in the Southern Cone of America and perspectives for contol. Aust. J. Agric. Res. 58:620630.

10. Germán, S. E., and Kolmer, J. A. 1994. Virulence phenotypes of Puccinia recondita f. sp. tritici in Uruguay. Plant Dis. 78:1139-1141.

11. Goyeau, H., Halkett, F., Zapater, M. F., Carlier J., and Lannou, C. 2007. Clonality and host selection in the wheat pathogenic fungus Puccinia triticina. Fungal Genet. Biol. 44:474-483.

12. Halkett, F., Simon, J. C., and Balloux, F. 2005. Tackling the population genetics of clonal and partially clonal organisms. Trends Ecol. Evol. 20:194-201.

13. Isard, S. A.,. Gage, S. H., Comtois, P., and Russo, J. M. 2005. Principles of the atmospheric pathway for invasive species applied to soybean rust. BioScience 55:851-861.

14. Johnson, T. 1956. Physiologic races of leaf rust of wheat in Canada 1931 to 1955. Can. J. Agric. Sci. 36:323-332.

15. Johnston, C. O., Caldwell, R. M., Compton, L. E., and Browder, L. E. 1968. Physiologic races of Puccinia recondita f. sp. tritici in the United States from 1926 through 1960. U. S. Dep. Agric. Tech. Bull. 1393:1-18.
16. Kolmer, J. A. 1998. Physiologic specialization of Puccinia recondita f. sp. tritici in Canada in 1996. Can. J. Plant Pathol. 20:176-181.

17. Kolmer, J. A. 2001. Molecular polymorphism and virulence phenotypes of the wheat leaf rust fungus Puccinia triticina in Canada. Can. J. Bot. 79:917-926.

18. Kolmer, J. A., Jin, Y., and Long, D. L. 2007. Leaf and stem rust of wheat in the United States. Aust. J. Agric. Res. 58:631-638.

19. Kolmer, J. A., Long, D. L., and Hughes, M. E. 2007. Physiological specialization of Puccinia triticina on wheat in the United States in 2005. Plant. Dis. 91:979-984.

20. Kolmer, J. A., Oelke, L. M., and Liu, J. Q. 2007. Genetics of leaf rust resistance in three Americano landrace-derived wheat cultivars from Uruguay. Plant Breed. 126:152-157.

21. Kolmer, J. A., and Ordoñez, M. E. 2007. Genetic differentiation of Puccinia triticina populations in Central Asia and the Caucasus. Phytopathology 97:1141-1149.

22. Kolmer, J. A., Singh, R. P., Garvin, D. F., Viccars, L., William, H. M., Huerta-Espino, J. H., Obonnaya, F. C., Raman, H., Orford, S., Bariana, H. S., and Lagudah, E. S. 2008. Analysis of the Lr34/Yr18 rust resistance region in wheat germplasm. Crop Sci. 48:1841-1852.

23. Liu, K., and Muse, S. V. 2005. PowerMarker: Integrated analysis environment for genetic marker data. Bioinformatics 21:2128-2129.

24. Long, D. L., and Kolmer, J. A. 1989. A North American system of nomenclature for Puccinia recondita f. sp. tritici. Phytopathology 79:525529.

25. Long, D. L., Leonard, K. J., and Hughes, M. E. 2000. Virulence of Puccinia triticina on wheat in the United States from 1996 to 1998. Plant Dis. 84:1334-1341.

26. Mantel, N. 1967. The detection of disese clustering and a generalized regression approach. Cancer Res. 27:209-220.

27. Marshall, D., and Sutton, R. L. 1995. Epidemiology of stripe rust, virulence of Puccinia striiformis f. sp. hordei, and yield loss in barley. Plant Dis. 79:732-737.

28. McCallum, B. D., Roelfs, A. P., Szabo, L. S., and Groth, J. V. 1999. Comparison of Puccinia graminis f. sp. tritici from South America and Europe. Plant Pathol. 48:574-581.

29. McIntosh, R. A., Yamazaki, Y., Devos, K. M., Dubcovsky, J., Rogers, J., and Appels, R. 2007. Catalogue of Gene Symbols for Wheat. 2007 Supplement. KOMUGI Integrated Wheat Science Database. Available online at http://www.shigen.nig.ac.jp/wheat/komugi/genes/symbolClassList.jsp.

30. Munkacsi, A. B., Stoxen, S., and May, G. 2008. Ustilago maydis populations tracked maize through domestication and cultivation in the Americas. Proc. R. Soc. 275:1037-1046.

31. Ordoñez, M. E., and Kolmer, J. A. 2007. Simple sequence repeat diversity of a world-wide collection of Puccinia triticina from durum wheat. Phytopathology 97:574-583.

32. Ordoñez, M. E., and Kolmer, J. A. 2009. Differentiation of molecular genotypes and virulence phenotypes of Puccinia triticina from common wheat in North America. Phytopathology 99:750-758.

33. Peakall, R., and Smouse, P. E. 2006. GENALEX 6: Genetic analysis in Excel. Population genetic software for teaching and research. Mol. Ecol. Notes 6:288-295.

34. Pritchard, J. K., Stephans, M., and Donnelly, P. 2000. Inference of population structure using multilocus genotype data. Genetics 155:945-959.

35. Rajaram, S., and Campos, A. 1974. Epidemiology of the wheat rusts in the western hemisphere. CIMMYT Res. Bull. No. 27.

36. Saari, E. E., and Prescott, J. M. 1985. World distribution in relation to economic losses. Pages 259-298 in: The Cereal Rusts. Vol. II. Diseases, Distribution, Epidemiology, and Control. A. P. Roelfs and W. R. Bushnell, eds. Academic Press, Orlando, FL.

37. Smouse, P. E., and Peakall, R. 1999. Spatial autocorrelation analysis of individual multiallele and multilocus genetic structure. Heredity 82:561573.

38. Sokal, R. R., and Rohlf, F. J. 1981. Biometry. W. H. Freeman, New York.

39. Straib, W. 1937. Las razas fisologicas de Puccinia glumarum en Sudamerica y su comportemiento en la infeccion comparado con el de las formas europeas. Arch. Fitoecnico Uruguay (Montevideo) 2:217-233.

40. Szabo, L. S., and Kolmer, J. A. 2007. Development of simple sequence repeat markers for the plant pathogenic rust fungus Puccinia triticina. Mol. Ecol. Notes 7:708-710.

41. Vallega, J. 1955. Wheat rust races in South America. Phytopathology 45:242-246.

42. Wellings, C. R., and McIntosh, R. A. 1990. Puccinia striiformis f. sp. tritici in Australasia: Pathogenic changes in the first 10 years. Plant Pathol. 39:316-325. 